\title{
Pós-positivismo: uma análise das convergências na literatura
}

\section{Legal postpositivism: an analysis of convergences in literature}

\author{
Orlando Luiz Zanon Júnior
}

\section{Resumo}

\begin{abstract}
O objetivo deste artigo é apresentar os pontos centrais sobre a ciência jurídica (ou teoria do Direito), geralmente compartilhados, em maior ou menor gradação, nas diversas correntes pós-positivistas. A discussão se justifica diante do cenário de crise do modelo teórico proposto pelo positivismo jurídico, consoante argumentado pelos principais autores do movimento chamado pós-positivismo, cabendo mencionar o substancialismo (Ronald Dworkin), o procedimentalismo (Robert Alexy) e o pragmatismo (Richard Posner). A ideia central é de que estes autores, embora partam de matrizes de raciocínio distintas, apresentam alguns pontos de concordância, ainda que com gradações e peculiaridades, os quais constituem noções centrais ao enfoque pós-positivista. Em síntese, foi diagnosticada a convergência majoritária quanto à adoção das teses do relacionamento entre direito e moral, da interdisciplinaridade, da multidimensionalidade dos critérios de julgamento e, ainda, da insuficiência da lógica dedutiva clássica (subsunção). Quanto à metodologia empregada, destaca-se que, na fase de investigação, foi utilizado o método indutivo, na fase de tratamento de dados, o cartesiano, e o texto final foi composto na base lógica dedutiva. Nas diversas fases da pesquisa, foram acionadas as técnicas do referente, da categoria, do conceito operacional e da pesquisa bibliográfica.
\end{abstract}

Palavras-chave: Pós-positivismo. Relação entre direito e moral. Interdisciplinaridade. Multidimensionalidade. Lógica subsuntiva.

\section{Abstract}

\begin{abstract}
The purpose of this article is to present the central points of legal Science (or legal theory) generally shared, to a greater or lesser degree, by the various post-positivist thesis. The discussion is justified because of the crisis of legal positivism, as argued by the main authors of Post-positivism movement, to mention substantialism (Ronald Dworkin), proceduralism (Robert Alexy) and pragmatism (Richard Posner). The central idea is that these authors, although starting from different points of view, present some points of agreement, although with gradations and peculiarities, which are central notions to the post-positivist approach. In summary, a majority convergence was found regarding the adoption of the thesis of the relationship between law and morality, of interdisciplinarity, of the multidimensionality of judgment criteria, and also of the insufficiency of the classical deductive logic (subsumption). As for the methodology, it is emphasized that in the investigation stage we used the inductive method, in the data processing phase we used the Cartesian method and the final text was composed on the basis of deductive logics. In the various stages of the research we used the techniques of the referent, the category, the operational concept and literature survey.
\end{abstract}

Keywords: Post-positivism. Relationship between law and morality. Interdisciplinarity. Multidimensionality. Subsumption.

\section{Introdução}

O objetivo deste artigo é apresentar os pontos centrais de quatro perspectivas sobre a ciência jurídica (ou teoria do Direito), geralmente incorporadas, em maior ou menor gradação, nas diversas correntes pós-positivistas, consistentes no relacionamento entre direito e moral, na interdisciplinaridade, na multidimensionalidade dos critérios de julgamento e, ainda, na insuficiência da lógica dedutiva clássica (subsunção).

Doutor em Ciência Jurídica pela UNIVALI. Dupla titulação em Doutorado pela UNIPG (Itália). Mestre em Direito pela UNESA. Pós-graduado pela UNIVALI e pela UFSC. Professor Programa de Pós-graduação da UNIVALI, da Escola da Magistratura de Santa Catarina (ESMESC) e da Academia Judicial (AJ). Membro da Academia Catarinense de Letra Jurídicas (ACALEJ). Juiz de Direito. Itajaí- SC- Brasil. E-mail: olzanon@yahoo.com.br. 
A temática se justifica diante do cenário de crise do modelo teórico proposto pelo positivismo jurídico, consoante argumentado pelos principais autores do movimento chamado pós-positivismo. No ponto, cabe mencionar que as proposições de superação paradigmática, no sentido da expressão oferecido por Thomas Samuel Kuhn (2009, p. 125 e 227), apresentam ampla divergência entre si. Entre as correntes de modificação mais difundidas no cenário brasileiro, importa mencionar o substancialismo (Ronald Dworkin), o procedimentalismo (Robert Alexy) e o pragmatismo (Richard Posner). A ideia central é de que estes autores, embora partam de matrizes de raciocínio distintas, apresentam alguns pontos de concordância, ainda que com gradações e peculiaridades, os quais constituem noções centrais ao enfoque pós-positivista.

Daí o primeiro item do texto tratar de um desses pontos de convergência teórica pós-positivista, consistente na tese de que existe alguma espécie de relação entre as questões jurídicas e as avaliações morais, com reflexos consideráveis nas decisões judiciais. $O$ assunto talvez seja um dos mais polêmicos na tradição jurídica ocidental, porém as abordagens recentes são no sentido de uma nova conformação entre juridicidade e moralidade, distinta daquela proposta nos moldes jusnaturalistas ou juspositivistas.

O segundo ponto deriva do anterior e consiste no argumento da abertura interdisciplinar entre a ciência jurídica e outros campos de estudo para compartilhamento de metodologias. Trata-se de uma discussão relacionada com o tema anterior, porém com espectro mais amplo.

O terceiro assunto segue a mesma sequência lógica anterior e, além de indicar o relacionamento da ciência jurídica com avaliações axiológicas (item 1) ou além de outras fronteiras (item 2), discorre sobre argumentos que apontam uma suposta invasão no próprio objeto de estudo (o direito) por elementos advindos de campos diversos (a moral, a economia etc.), que passam a assumir a força de critérios de decisão.

O quarto, por fim, cabe indicar uma decorrência dos itens anteriores, consistente no argumento da insuficiência da lógica clássica (o chamado modelo subsuntivo) como método de aplicação jurídica.

Contudo, antes de inaugurar tais tópicos, em discussões deste tipo, é oportuno justificar a opção teórica de conferir status científico para os estudos sobre o Direito, a qual está baseada no argumento de se entender altamente recomendável sugerir um esforço de seriedade e coerência no desenvolvimento de pesquisas nessa área específica, de modo a que os juristas ultrapassem discussões superficiais baseadas em slogans arraigados, carentes de embasamento fático, para buscar a justificação empírica de suas teses, ainda que mediante o emprego de ferramentas geralmente utilizadas por economistas, psicólogos, sociólogos e outros pesquisadores. Justamente nesse viés, tem ganhado destaque a área alcunhada de Jurimetria, para indicar a importância dos indicadores estatísticos nos estudos jurídicos (NUNES, 2016, p. 86). No ponto, não é ocioso lembrar a lição de Bertrand Russel, no sentido de que uma construção teórica carente de embasamento empírico pode ser representada como uma pirâmide invertida, na qual o princípio fundamental reside em sua ponta de sustentação e, assim, acaso desconstituído, implica a ruína de toda a articulação (RUSSEL, 2017, p. 286).

De qualquer modo, mesmo a negação de cientificidade a este campo de estudo não prejudica a análise aqui proposta, a qual prossegue ainda que o leitor opte por classificá-la como um ramo da Filosofia ou mesmo uma teoria carente de algum componente de cientificidade (como, por exemplo, deixar atender ao critério de falseabilidade empírica) (POPPER, 2008, p. 41-44). Isto porque o conteúdo deste artigo não se perde se o leitor substituir as expressões que referem ciência jurídica por outra mais adequada à sua linha de pensamento, a exemplo de teoria ou filosofia jurídica.

Feita essa ressalva, quanto à metodologia empregada, destaca-se que, na fase de investigação, foi utilizado o método indutivo, na fase de tratamento de dados, o cartesiano, e o texto final foi composto na base lógica dedutiva. Nas diversas fases da pesquisa, foram acionadas as técnicas do referente, da categoria, do conceito operacional e da pesquisa bibliográfica (PASOLD, 2011).

\section{Relação entre Direito e moral}

O presente item discorre sobre a posição prevalecente entre pós-positivistas acerca da discussão em torno da existência (ou não) de alguma relação necessária entre os critérios formais de julgamento (Direito) 
e influxos axiológicos (moral/ética). O tema se apresenta como uma constante na história dos debates sobre as fronteiras e os limites da atividade decisória, notadamente na esfera judicial.

Para contextualizar, importa mencionar que o paradigma do jusnaturalismo tem como uma de suas bases centrais o argumento da existência do Direito natural, composto por um conjunto de princípios morais universais e, outrossim, superiores aos critérios de julgamento artificialmente criados pela cultura humana (SCHIOPPA, 2014, p. 238). Segundo Norberto Bobbio (2016, p. 223), "direito natural é aquela parte do direito cuja origem (no duplo sentido de fonte e de fundamento) independe da obra criadora do homem". Contudo, os defensores do paradigma do juspositivismo apresentaram duras críticas em face da proposição jusnaturalista, com base em diversas perspectivas.

De um lado, os juspositivistas argumentaram que a existência de um conjunto de princípios morais era uma pressuposição metafísica, carente de demonstração empírica, de modo a representar uma falha no perfil científico que deveria reger a produção do conhecimento. Na sua visão, isto atentaria contra o binômio de descrição e prescrição nos estudos, haja vista que confunde a narrativa fiel de uma realidade com a proposição de respostas para os casos problemáticos. Neste particular, igualmente se adiciona o argumento de que a tese jusnaturalista representa uma recaída na falácia naturalista explicitada por David Hume, consistente na tese metalógica segundo a qual não se pode extrair leis axiológicas ou morais universais (o que deve ser) da observação empírica e científica da natureza (o que é) (FERRAJOLI, 2014, p. 205). Dessas considerações, exsurgiu uma conformação específica do postulado das fontes sociais do Direito.

De outro lado, os juspositivistas ainda argumentaram que a possibilidade de invocação de supostos princípios morais, oriundos de um plano metafísico, acaba por minar a certeza do Direito e, outrossim, atenta contra a segurança jurídica, que é precisamente o elemento justificador central do sistema (DIMOULIS, 2011, p. 90-98). Segundo eles, a tese da existência de um ordenamento natural está calcada numa confusão entre as perspectivas do observador, que estuda um fenômeno de uma distância isenta, e do partícipe, que está implicado na análise em busca da melhor solução para cada caso jurídico. Outrossim, a recomendação seria no sentido de se respeitar a autoridade formal, de modo a evitar subjetivismos baseados em postulados axiológicos, expressa no argumento adicional da separação entre Direito e moral (FERRAJOLI, 2012, p. 14).

Ambas as linhas argumentativas acima, juntamente com suas decorrências laterais, foram objeto de críticas pelos defensores de novas conformações teóricas para compreensão do fenômeno jurídico, coletivamente chamadas de pós-positivismo.

Inicialmente, os pós-positivistas argumentam que a vinculação entre moralidade e juridicidade não é um fruto da imaginação metafísica, a qual remanesce adstrita à proposição jusnaturalista. Diferentemente, há uma prevalência do argumento de que, efetivamente, não só o direito positivo, mas também os postulados axiológicos, são construções culturais da humanidade e, assim, ambas podem representar o objeto de pesquisa relevante para o estudo do fenômeno jurídico.

Nessa linha de pensamento, mesmo Dworkin, considerado defensor do uso de postulados morais como critérios de julgamento em casos classificados como difíceis ou controversos, afasta qualquer invocação do Direito natural. Na sua visão, também as considerações morais são decorrentes de construção artificial da humanidade, cuja relevância é crucial para a adequada resolução das causas judiciais. Isto implica, grosso modo, uma adesão pós-positivista à tese da fonte social do Direito, ampliando-a para abraçar também a moralidade (DWORKIN, 2007, p. 204-208 e 271-272).

Igualmente Posner (2012, p. 27-28), embora um duro crítico quanto à utilidade das pesquisas acadêmicas sobre moralidade política, refere que, "[...] no passado e no presente, toda sociedade e toda subcultura dentro de uma sociedade tiveram seu código moral. Este código, porém, sempre foi moldado pelas exigências da vida nessa sociedade, e não pelo vislumbre de uma fonte superior e universal de obrigações morais."

Feita consideração, cabe prosseguir referindo que o argumento pós-positivista é no sentido da inviabilidade de se cindir os aspectos descritivos e prescritivos de uma ciência, haja vista que a produção do conhecimento é um empreendimento humano, voltado à resolução de um problema. Nessa ótica, são 
tecidas críticas ao modelo juspositivista calcadas no entendimento de que o Direito não é apenas um corpo sistemático de regras positivadas em estatutos ou precedentes anteriores, mas sim consubstancia uma atividade criativa de uma resposta resolutiva para um determinado caso concreto, calcada em um conjunto de argumentos, dentre eles os de cunho axiológico (NUNES, 2016, p. 27). Nessa linha de raciocínio, não seria viável (ou mesmo útil) uma abordagem científica lastrada apenas no esforço de descrever uma realidade, porquanto todo julgamento envolve a prescrição de uma solução para determinado problema social.

Mais do que isto, além da junção inafastável das fases de prescrição e descrição, cabe ainda referir que uma leitura mais fiel da realidade aponta, inegavelmente, para a incidência de influxos morais na atividade decisória. Evidentemente, os juspositivistas efetuaram uma abordagem desse aspecto do cenário jurídico, esclarecendo que legisladores, juízes e demais operadores dos mecanismos do direito efetivamente levam em consideração aspectos morais como padrões de julgamento, embora reneguem o caráter jurídico desse procedimento (KELSEN, 1986, p. 148). Na sua visão, o emprego de critérios morais significa o ingresso de padrões externos ao Direito para fins de justificação de uma decisão judicial, porém tal posicionamento é criticado pelas correntes que almejam a substituição do positivismo jurídico, precisamente porque se trata de uma asserção inviável quanto à efetiva descrição científica da realidade.

$\mathrm{Na}$ visão dos críticos, cabe considerar que há estudos empíricos apontando para as influências da moral no comportamento humano, mormente nos atos decisórios, de modo a recomendar a construção de teorias mais adequadas para lidar com esse aspecto do fenômeno jurídico (STANLEY et al., 2018). Para eles,

o facto de existirem especificidades no raciocínio jurídico (e que se manifestam não unicamente sob uma perspectiva institucional, embora seguramente esta seja decisiva) permite que se fale de uma relativa autonomia, mas não de uma total independência do raciocínio jurídico relativamente ao moral. (ATIENZA, 2014b, p. 312).

Em síntese,

ao deparar com um caso, inicia-se o processo de descoberta do magistrado, em que intuições podem ter um papel importante. Porém, o processo de descoberta inclui a necessidade de justificação: o juiz precisa primeiro convencer a si mesmo de que a escolha que intuiu faz sentido. Para tanto, reúne argumentos que articulem juízos de valor que permitem defender sua escolha como jurídica, justa ou razoável. (HORTA; COSTA, 2017, p. 290).

Em outros termos, os pós-positivistas assumem que a realidade concreta aponta para a existência de uma relação fática entre direito e moral e, diante dessa descrição científica, pretendem construir proposições (SHOOK, 2002, p. 25).

Dando prosseguimento na exposição dos pontos de crítica, cabe ainda referir que os pós-positivistas entendem que não há como, de fato, separar as posturas do observador e do participante em um determinado objeto de pesquisa. Na sua visão, um cientista não tem condições efetivas de assumir uma postura externa e neutra perante o fenômeno que investiga, como se fosse apenas um observador isento, haja vista que, em algum grau, estará imbricado como participante do procedimento de conhecer, descrever e prescrever soluções sobre um determinado objeto de pesquisa. Com efeito,

a descrição de um cientista como alguém completamente imparcial, neutro e sem desejos é bastante imprecisa. É verdade que os cientistas não devem corromper experimentos para garantir que se produzam os resultados previstos. Todavia, [o pragmatista William] James explica que as decisões científicas são produzidas apenas porque as pessoas têm de solucionar problemas. (SHOOK, 2002, p. 128).

De acordo com a maioria dos adeptos do pós-positivismo, a tarefa do cientista é tentar resolver um problema na descrição de determinado fenômeno, visando instrumentalizar alguma resposta com relação ao mesmo. Justamente por isto, dificilmente seria viável classificar a postura de um cientista apenas como um observador, sem qualquer participação no empreendimento que desenvolve, mormente em se tratando de estudos jurídicos. 
Em razão das críticas antes expostas, é possível afirmar as tendências pós-positivistas gerais quanto à relação entre moralidade e juridicidade nos seguintes termos: a) adesão à tese das fontes sociais do Direito e, ainda, acréscimo de que também a moralidade é um fato cultural observável empiricamente, que exerce importante influência na tomada de decisão pelos operadores jurídicos; b) rejeição do argumento da separação entre Direito e moral, haja vista que, sob o ponto de vista descritivo, a observação empírica revela importantes influências axiológicas nas atividades dos juristas, com considerável impacto nas políticas públicas, bem como do ponto de vista prescritivo, porquanto seria recomendável a análise qualitativa das opções para o governo coletivo, de modo a atender tendências axiológicas de cada comunidade específica; e, c) inviabilidade de completa separação entre as posturas do observador e do partícipe, mormente tratando-se do empreendimento jurídico, caracterizado por refletir o empenho dos juristas na construção de critérios de julgamento adequados às políticas públicas avaliadas tecnicamente e axiologicamente, visando o bem da coletividade.

\section{Interdisciplinaridade}

Neste segundo item, cabe referir a tendência pós-positivista em aceitar a abertura do sistema jurídico não apenas a critérios de moralidade política, mas também a padrões de conduta diversos, estudados por outras áreas da ciência (POSNER, 2011, p. VIII).

Na perspectiva do movimento do pós-positivismo, as fronteiras do ordenamento jurídico estão abertas a parâmetros de julgamento extraídos de outros campos do saber e, justamente por isto, a ciência jurídica merece abordar criticamente tais influências. Importa uma descrição da realidade, ou seja, uma apresentação de como determinados agentes se comportam de acordo com influências de outros campos do conhecimento e, também, adicionalmente, prescrever soluções e recomendações com relação à adequação, ou não, desses influxos nas atividades jurídicas.

Dentre os campos de estudos interdisciplinares mais desenvolvidos, cabe mencionar a Análise Econômica do Direito (Economic Analisys of Law), também chamada de Direito e Economia (Law \& Economics). Trata-se de abordagem caracterizada pelo emprego de instrumentos desenvolvidos por economistas para aperfeiçoar as pesquisas jurídicas e otimizar o funcionamento das instituições políticas (notadamente a jurisdição).

Assim como os dois campos de estudo envolvidos (Direito e economia), essa proposta interdisciplinar apresenta os aspectos descrito e prescritivo da produção do conhecimento, sendo que, de um lado, o "Direito e Economia Positivo se ocupa das repercussões do Direito sobre o mundo real dos fatos", enquanto, de outro, "o Direito e Economia Normativo se ocupa de estudar se, e como, noções de justiça se comunicam com os conceitos de eficiência econômica, maximização da riqueza e maximização de bem-estar". (SALAMA, 2018, p. 4).

Um aspecto controvertido deste approach consiste em estimular decisões políticas e jurídicas que propiciem a maximização da produção e da riqueza em sentido sistêmico, em favor de toda a sociedade (ou mesmo no cenário global, se possível). Sem embargo,

a política econômica consiste em escolher que regras e procedimentos legais ou estruturas administrativas serão capazes de maximizar o valor da produção. No entanto, detectar os efeitos de aletações de posições jurídicas sobre o funcionamento do sistema econômico não é fácil, embora esteja sendo feito progresso como resultado das pesquisas de economistas engajados na nova disciplina 'Direito e Economia' (COASE, 2017, p. 29).

Cabe acentuar a existência de entendimento no sentido de que, mesmo diante de sólidos dados empíricos em favor de determinada solução, isto não afasta a importância de discussões axiológicas. Nesse sentido, Coase (2017, p. 153) já havia destacado que "os problemas da teoria econômica do bem estar (sic) devem ser dissolvidos, no final, num estudo da estética e da moral".

De outra margem, outras áreas têm, historicamente, influenciado as atividades de produção do Direito com impactos na construção de critérios impessoais gerais (positivação ou processo legislativo), como também na resolução de casos concretos (aplicação ou processo judicial). 
Dentre elas, vem ganhando recente destaque a chamada Jurimetria, que estabelece os vínculos entre os estudos jurídicos e a estatística. Trata-se da "disciplina do conhecimento que utiliza a metodologia estatística para investigar o funcionamento de uma ordem jurídica", cujo objeto "não é a norma jurídica isoladamente considerada, mas sim a norma jurídica articulada, de um lado, como resultado (efeito) do comportamento dos reguladores e, de outro, como estímulo (causa) no comportamento de seus destinatários" (NUNES, 2016, p. 115).

Esses estudos têm sido apresentados como de grande relevância na gestão judiciária, notadamente a partir dos esforços do Conselho Nacional de Justiça (CNJ) para extrair dados estatísticos referentes ao funcionamento do Poder Judiciário brasileiro, de modo a revelar situações de grande utilidade prática, consoante divulgado no relatório Justiça em Números, editado anualmente. Dentre os dados obtidos, registrouse que, atualmente, há quase 100 (cem) milhões de processos em tramitação na jurisdição brasileira, dentre os quais aproximadamente $40 \%$ (quarenta por cento) possuem, em algum de seus polos, um dos 100 (cem) grandes litigantes, grupo composto, preponderantemente, pelos entes públicos, instituições financeiras e concessionárias de serviços públicos. ${ }^{1}$

Ainda mais recentemente, a área da Tecnologia da informação tem apresentado propostas de soluções para o campo do Direito, constituindo o que se convencionou chamar de Direito e Informática. Os estudos mais atuais, aliás, apontam para o emprego de inteligência artificial para auxiliar na ágil seleção de decisões padronizadas para os casos identificados como repetitivos. Um exemplo dessa linha de estudos é o desenvolvimento o sistema Victor de inteligência artificial, sob a coordenação do Supremo Tribunal Federal (BRASIL. STF, 2018).

O fenômeno chamado de judicialização da saúde tem, igualmente, recomendado a abertura de uma relação entre a ciência jurídica e as da saúde (Medicina, Farmácia, Biologia etc.). Com efeito, o campo de estudos de Direito e Saúde diz respeito ao emprego de conclusões técnicas das ciências da saúde como critérios para deliberação sobre os pedidos de condenação ao custeio de tratamentos e medicamentos para determinadas doenças. Há um estímulo para que os magistrados, com apoio em corpo técnico específico, pautem suas decisões na chamada medicina baseada em evidências, num esforço para evitar erros quanto à alocação de recursos públicos ou de operadoras de planos de saúde com medidas consideradas majoritariamente ineficientes ou meramente paliativas. Inclusive, no âmbito do estado de Santa Catarina, estudos desse tipo ensejaram a criação do Núcleo de Apoio Técnico (NAT), que visa oferecer subsídios médicos para tomada de decisões corretas na área da saúde (WISBECK; MEDEIROS; COSTA; ARAÚJO, 2018).

Outra área de estreita interligação com o direito é a Psicologia, empregada como instrumental de conhecimento técnico em pontos extremamente sensíveis da atividade judicial, a exemplo dos casos criminais, familiares e da infância e juventude, dentre outros. De modo similar, merecem menção os recentes desenvolvimentos na área da Neurolaw (neurologia e direito) (GOODENOUGH, 2010).

Entretanto, como em todos os demais aspectos em discussão neste texto, cabe referir que há exceções à aceitação da interdisciplinaridade do Direito com outros campos do saber. No cenário brasileiro, é digna de nota a resistência de Lenio Luiz Streck que, embora seja reconhecido como um pós-positivista (mas não neopositivista), rejeita a abertura do ordenamento jurídico para critérios econômicos e políticos, dentre outros. Na sua visão, a decisão judicial merece estar calcada exclusivamente em regras e princípios jurídicos, devidamente filtrados pela atividade legiferante, ainda que co-originários com valores morais, vedado o recurso a padrões externos da política e da economia, dentre outros. Com essa limitação, sua pretensão é majorar a autonomia do Direito e, assim, reduzir a discricionariedade judicial, a qual, na sua opinião, decorreria também da invocação desses padrões exteriores, que atuam como predadores externos da atividade judicial (STRECK, 2011, p. 211).

O quantitativo de processos é uma aproximação livre para 2018, considerando que, segundo o relatório Justiça em Números 2017 , o ano de 2016 findou com cerca de 79,7 milhões de processos em tramitação, conforme BRASIL. CNJ. Justiça em Números 2016. Complementando, sobre o percentual de participação dos grandes litigantes, recomenda-se a visualização do seguinte vídeo: AMB. Não Deixe a justiça parar. 
Para concluir este item, é possível diagnosticar uma tendência pós-positivista majoritária quanto à promoção da interdisciplinaridade da ciência jurídica com outros campos do saber ante a aceitação de influências de critérios técnicos externos para fundamentar deliberações judiciais, de modo a firmar os campos da Análise Econômica do Direito (AED), Jurimetria, Direito e Informática, Direito e Saúde, Neurolaw etc.

\section{Multidimensionalidade do Direito}

Este terceiro item refere-se à percepção pós-positivista de que o sistema jurídico não é formado apenas por um conjunto de normas da modalidade regra jurídica, mas também por outros padrões de julgamento, a depender da abordagem.

Sobre esse tema, o argumento dos juspositivistas é no sentido de que o ordenamento jurídico é composto exclusivamente por regras jurídicas, geralmente conceituadas como esquemas de interpretação ou razões definitivas de dever ser, aplicáveis mediante raciocínio lógico dedutivo, ou seja, subsunção (KELSEN, 2006, p. 4). Inclusive, eles "não necessitam de uma teoria da argumentação jurídica. Basta-lhes a lógica dedutiva, que alguns chegam a reduzir inclusive a um só tipo de argumento: o modus ponens, o silogismo judicial". (ATIENZA, 2014b, p. 35).

Há alguns abrandamentos na tese da unidimensionalidade. Por exemplo, Herbert Hart, após debate com Ronald Dworkin, admitiu que existem também outros critérios de julgamento na periferia do sistema, embora o núcleo duro do ordenamento seja composto por regras jurídicas primárias e secundárias (HART, 2009 , p. 128). Outro exemplo é a proposta de Luigi Ferrajoli (2011, p. 532-533), no sentido de que a ordem jurídica seria acrescida, também, de princípios jurídicos, desde que devidamente filtrados formalmente através do processo legislativo, embora também estes sejam aplicados por subsunção, diferindo das regras apenas com relação ao estilo de redação.

O movimento pós-positivista apresenta uma resposta diferente, consubstanciada na ampla aceitação da inclusão da dimensão dos princípios jurídicos, ao lado (como complemento) e atrás (como fundamento) das regras jurídicas (ALEXY, 2008a, p. 65). Exemplificativamente, a posição de Robert Alexy (2008b, p. 85) é que as normas jurídicas são classificadas em dois tipos básicos, consistentes nas regras jurídicas aplicáveis por subsunção para resolver casos fáceis e nos princípios jurídicos empregados por ponderação para resolução de causas difíceis.

Há autores, ainda, que defendem a inclusão de outros padrões de julgamento além daqueles dois antes mencionados, sob o argumento de que o sistema jurídico não é fechado, de modo a contemplar também parâmetros políticos e técnicos diversos, a depender das peculiaridades de cada caso concreto. Nesse sentido, Ronald Dworkin (2007, p. 35-36;119) argumenta pela maior extensão e abertura do sistema jurídico para admitir que merecem ser considerados como critérios de julgamento todos aqueles efetivamente empregados pelos juízes para resolver casos concretos, sejam regras, princípios, políticas, , sejam outros. Contudo, refere que a guia mestra merece ser a principiológica, porquanto veicula os valores caros a determinada comunidade (DWORKIN, 2007, p. 133).

Nessa linha de raciocínio, "o Direito não pode ser reduzido a um conjunto de normas editado por autoridades competentes e deve ser visto, sim, como um aparato de solução de conflitos, no qual a lei desempenha um papel importante, porém não suficiente". (NUNES, 2016, p. 113). De acordo com tal entendimento, "os juízes utilizam múltiplos e variados critérios para chegar a formular (e justificar) a norma que lhes resolve o caso. Esses critérios que utilizam para construir a norma do caso, juntos com ela mesma, são candidatos para chegar a ser normas de origem judicial". (REGLA, 2013, p. 132).

Ou seja,

os juristas não dispõem - ou não dispõem sempre - de normas que possam, sem mais, aplicar à situação: os materiais em bruto, dados pelo sistema, são (pelo menos em certas ocasiões) somente enunciados (artigos de leis, textos jurisprudenciais, etc.) que eles têm que transformar em normas (na norma aplicável ao caso) por meio de interpretação (ATIENZA, 2014b, p. 293). 
Seguindo tal premissa, a Teoria Complexa do Direito sustenta que o ordenamento jurídico é composto por todas as fontes jurídicas legitimamente aceitas em determinada comunidade. A depender das opções políticas estabelecidas em cada coletividade organizada, são artificialmente selecionados determinados critérios de julgamento materiais e formais, sob uma estrutura orbital de argumentos passíveis de serem legitimamente empregados para justificação das decisões judiciais. Por exemplo, no cenário brasileiro, as fontes materiais seriam os princípios jurídicos, a doutrina e os costumes, enquanto as formais se compõem de textos legais, acervo jurisprudencial e políticas públicas, com graus de eficácia argumentativa distintos. Sem olvidar que, em outros cenários, o rol de fontes jurídicas tende a ser outro ou apresentar graus de força diferentes, a exemplo da inclusão da sharia com máxima importância em determinados países de tradição muçulmana (ZANON, 2015, p. 159-163 e 190-194).

Esta última tendência, referente à aceitação mais ampla de parâmetros de conduta, tem ganhado maior destaque ultimamente. De acordo com ela, "o Direito não pode ser reduzido a um conjunto de normas editado por autoridades competentes e deve ser visto, sim, como um aparato de solução de conflitos, no qual a lei desempenha um papel importante, porém não suficiente". (NUNES, 2016, p. 113).

Outrossim, importa encerrar este item referindo que o terceiro enfoque amplamente majoritário do conjunto das proposições pós-positivistas é caracterizado pela aceitação de outros critérios de julgamento, além (ou em substituição) das regras jurídicas, com características, eficácia e modos de aplicação diferenciados, de modo a conceber um sistema jurídico multidimensional, ao invés de piramidal.

\section{Insuficiência da lógica formal dedutiva}

A quarta característica geral do pós-positivismo a ser destacada neste texto se expressa no entendimento de que a lógica formal dedutiva (subsunção) é insuficiente para descrever a complexidade da operação de deliberação jurídica e, consequentemente, não oferece soluções suficientemente sofisticadas para auxiliar o empreendimento jurisdicional (ATIENZA, 2014a, p. 8-9).

Antes de inaugurar a discussão, importa diferenciar o processo decisório nos contextos de descoberta e de justificação. O primeiro deles diz respeito à fase intelectual de construção de uma resposta para resolução de determinado problema. Esse momento ainda não é plenamente compreendido, porém estudos mais recentes sobre o funcionamento do cérebro apontam para o elevado impacto de questões axiológicas na tomada de decisões. O segundo estágio é o da construção de justificativas para a sustentação de determinada opção, mediante a articulação de argumentos relevantes (ATIENZA, 2014b, p. 128-137).

Feito esse esclarecimento inaugural, cabe referir que o positivismo jurídico adota uma visualização forte da distinção entre os contextos da descoberta e da justificação, em razão de sua interpretação da falácia naturalística de David Hume, antes mencionada. Assim, de um lado, compreende as dificuldades inerentes à discussão científica sobre a fase da descoberta, embora estejam surgindo novos estudos sobre esse tema (STRUCHINER, 2014, p. 171-172). Por outro lado, quanto ao contexto da justificação, o argumento central é de que cabe ao magistrado a incumbência de produzir a motivação de cada decisão segundo a lógica dedutiva clássica (modus ponens), geralmente chamada de subsunção. Segundo as correntes juspositivistas mais difundidas, a regra jurídica é uma orientação de decisão preestabelecida pelo legislador, a qual consubstancia a premissa maior, enquanto os fatos são os pressupostos menores, cabendo ao julgador a tarefa de articulação entre ambos, para se alcançar a solução lógica e racional quanto à legalidade, perante o problema em exame.

As abordagens pós-positivistas divergem consideravelmente, com ampla gama de variação com relação à descrição da atividade deliberativa e, consequentemente, no tocante à proposição de soluções para apresentação de justificativas. Parte-se do pressuposto de que

ninguém mais acredita realmente que as operações realizadas pelo juiz para interpretar o direito sejam apenas lógicas, no sentido estrito da palavra, isto é, que sejam operações de dedução de certas conclusões a partir de determinadas premissas; em outras palavras, que a atividade do juiz seja meramente mecânica ou automática. (BOBBIO, 2016, p. 118). 
Uma primeira diferenciação diz respeito à compreensão da atividade decisória como um empreendimento destinado à construção de uma resposta, de acordo com um conjunto multidimensional de critérios de julgamento. Para os pós-positivistas,

o enunciado interpretativo emitido por um juiz não descreve algo pré-existente, mas tão-pouco pode ver-se como uma prescrição, visto que se trata mais exatamente de uma criação peculiar, um desenvolvimento guiado - embora não pré-determinado em todos os seus aspectos - por certos critérios (algo intermédio entre criar e aplicar) e que, de certo modo, tem algo de descritivo e prescritivo. (ATIENZA, 2014b, p. 69).

Essa visualização implica a atenuação da diferenciação dos contextos da descoberta e da justificação, mormente sob a ótica do juiz, encarregado de produzir uma decisão para resolução de um caso concreto. Em outras palavras,

a distinção entre as razões explicativas e as justificativas (em que consiste a distinção entre contexto de descoberta e contexto de justificação) parece estar feita na perspectiva de um observador externo, digamos, de um jurista teórico ou de um sociólogo. Mas poderia ser efectuada na perspectiva do próprio juiz? Provavelmente não, ou pelo menos não da mesma maneira. (ATIENZA, 2014b, p. 253).

Precisamente por isto, "ao se entender por positivismo jurídico apenas o 'codicismo', a teoria da interpretação mecânica da lei, creio que teriam razão aqueles que sugerem descartá-lo, pela ótima razão de que ele é desmentido pelos fatos". (BOBBIO, 2016, p. 154). Daí que, sob um viés pragmático, Richard Posner (2012, p. 324) afirma que "a pauta da Corte [Suprema] é dominada por causas constitucionais difíceis, e só os ingênuos pensam que as decisões dessas causas são predominantemente determinadas por métodos de investigação desinteressados, apolíticos e 'independentes das tendências do observador'."

Por outro lado, importa assinalar que a insuficiência da subsunção não implica que se deve adotar a falácia irracionalista, a qual está calcada no argumento de que, inviável o mero silogismo lógico dedutivo, a atividade deliberativa judicial merece ser vista como mero decisionismo com base em premissas puramente subjetivistas (ATIENZA, 2014b, p. 130). Ao contrário, é possível articular modelos de restrição psicológica da atividade decisória, mormente na fase de justificação das deliberações (ATIENZA, 2014b, p. 133-134). Sem embargo, outro aspecto tipicamente pós-positivista consiste em defender a construção de critérios para ponderação de princípios jurídicos e, eventualmente, de outros padrões de julgamento, como metodologia para resolução do caso processual.

Nessa perspectiva, propõe-se a visualização da complexidade da atividade de deliberação judicial, que ultrapassa a redução do fenômeno a um silogismo subsuntivo. $O$ argumento é de que a lógica formal integra o processo como elemento importante, porém não exclusivo, cabendo também abordagens quanto ao processo argumentativo e, ainda, concernente à postura pragmática do julgador, por ser empreendedor na busca por uma determinada consequência considerada adequada ao ordenamento jurídico.

Em síntese, a proposição pós-positivista é de que a atividade decisória merece ser estudada quanto aos contextos da descoberta e da justificação, para fins de esclarecer a complexidade do fenômeno em seus aspectos lógico, argumentativo e pragmático (ATIENZA, 2014b, p. 13; 127). Nessa ótica, cabe assinalar que a motivação de uma decisão não responde apenas a uma lógica subsuntiva, mas consubstancia uma articulação de diversos padrões de julgamento para justificar uma decisão em determinado sentido, considerando seus efeitos no contexto da aplicação.

\section{Conclusão}

O objetivo deste artigo foi apresentar os aspectos principais de quatro abordagens sobre a ciência jurídica (ou teoria do Direito) incorporadas, em maior ou menor gradação, nas mais diversas correntes pós-positivistas, consistentes no relacionamento entre Direito e moral, na interdisciplinaridade, na multidimensionalidade dos critérios de julgamento e, ainda, na insuficiência da lógica dedutiva clássica (subsunção). 
No concernente ao primeiro aspecto, a relação entre Direito e moral, restaram expostas as seguintes tendências pós-positivistas gerais : a) adesão a tese das fontes sociais do Direito e, ainda, acréscimo de que também a moralidade é um fato cultural observável empiricamente, que exerce importante influência na tomada de decisão pelos operadores jurídicos; b) rejeição do argumento da separação entre juridicidade e moralidade, haja vista que, sob o ponto de vista descritivo, a observação empírica revela importantes influências axiológicas nas atividades dos juristas, com considerável impacto nas políticas públicas, bem como do ponto de vista prescritivo, de maneira que seria recomendável a análise qualitativa das opções para o governo coletivo, de modo a atender tendências axiológicas de cada comunidade específica; e, c) inviabilidade de completa separação entre as posturas do observador e do partícipe, mormente em se tratando do empreendimento jurídico, caracterizado por refletir o empenho dos juristas na construção de critérios de julgamento adequados às políticas públicas avaliadas tecnicamente e axiologicamente, visando o bem da coletividade.

Sobre o segundo item, diagnosticou-se uma tendência pós-positivista majoritária, quanto à promoção da interdisciplinaridade da ciência jurídica com outros campos do saber, ante a aceitação de influências de critérios técnicos externos para fundamentar deliberações judiciais, de modo a firmar os campos da Análise Econômica do Direito (AED), Jurimetria, Direito e Informática, Direito e Saúde, Neurolaw etc.

No tocante ao terceiro item, referiu-se um enfoque amplamente majoritário do conjunto das proposições pós-positivistas pela aceitação de outros critérios de julgamento, além (ou em substituição) das regras jurídicas, com características, eficácia e modos de aplicação diferenciados, de modo a conceber um sistema jurídico multidimensional, ao invés de piramidal. Contudo, foi registrada especial divergência neste particular, no sentido de que eventuais influxos externos poderiam contaminar a autonomia jurídica e, ainda, majorar a discricionariedade judicial.

No tocante ao quarto aspecto, observou-se que a atividade decisória merece ser estudada quanto aos contextos da descoberta e da justificação, para fins de esclarecer a complexidade do fenômeno em seus aspectos lógico, argumentativo e pragmático. Nessa perspectiva, assinalou-se que a motivação de uma decisão não responde apenas a uma lógica subsuntiva, mas sim a uma articulação de diversos padrões de julgamento para justificar uma decisão em determinado sentido, considerando seus efeitos no contexto da aplicação.

\section{Referências}

ALEXY, Robert. Constitucionalismo discursivo. 2. ed. Porto Alegre: Livraria do Advogado, 2008a.

ALEXY, Robert. Teoria dos direitos fundamentais. São Paulo: Malheiros, 2008b.

ASSOCIAÇÃO DOS MAGISTRADOS BRASILEIROS. Não Deixe a justiça parar. [S.I.], 13 ago. 2015. Disponível em: https://www.youtube.com/watch?v=B1fMnw0wxOg. Acesso em: 07 ago. 2018.

ATIENZA, Manuel. As razões do direito: teoria da argumentação jurídica. 2. ed. Rio de Janeiro: Forense, 2014a.

ATIENZA, Manuel. O direito como argumentação. Lisboa: Escolar, 2014b.

BOBBIO, Norberto. Jusnaturalismo e positivismo jurídico. São Paulo: Unesp, 2016.

BRASIL. Conselho Nacional de Justiça - CNJ. Justiça em Números 2016. Brasília, 2016. Disponível em: http://www.cnj.jus.br/programas-e-acoes/pj-justica-em-numeros. Acesso em: 07 ago. 2018.

BRASIL. Supremo Tribunal Federal. Inteligência artificial vai agilizar a tramitação de processos no STF. Brasília, 30 maio 2018. Disponível em: http://www.stf.jus.br/portal/cms/verNoticiaDetalhe. asp?idConteudo=380038. Acesso em: 07 ago. 2018.

COASE, Ronald H. A firma, o mercado e o direito. 2. ed. Rio de Janeiro: Forense, 2017.

DIMOULIS, Dimitri. Manual de introdução ao estudo do direito. 4. ed. São Paulo: RT, 2011. 
DWORKIN, Ronald. Levando os direitos a sério. 2. ed. São Paulo: Martins Fontes, 2007a.

DWORKIN, Ronald. O império do direito. São Paulo: Martins Fontes, 2007b.

FERRAJOLI, Luigi. Garantismo: uma discussão sobre direito e democracia. Rio de Janeiro: Lumen Juris, 2012.

FERRAJOLI, Luigi. Principia iuris: teoría del derecho y de la democracia. Madrid: Trotta, 2011. v.1 GOODENOUGH, Oliver R.; TUCKER, Micaela. Law and cognitive neuroscience. Annual review of law and social science, [S.I.], v. 6, p. 61-92, 2010.

HART, H. L. A. O conceito de direito. São Paulo: Martins Fontes, 2009.

HORTA, Ricardo de Lins; COSTA, Alexandre Araújo. Das teorias da interpretação à teoria da decisão: por uma perspectiva realista acerca das influências e constrangimentos sobre a atividade judicial. Opinião Jurídica, Fortaleza, n. 20, p. 271-297, jan./jun. 2017.

KELSEN, Hans. Teoria geral das normas. Porto Alegre: Sergio Antonio Fabris, 1986.

KELSEN, Hans. Teoria pura do direito. 7. ed. São Paulo: Martins Fontes, 2006.

KUHN, Thomas S. A estrutura das revoluções científicas. São Paulo: Perspectiva, 2009.

NUNES, Marcelo Guedes. Jurimetria: como a estatística pode reinventar o direito. São Paulo: RT, 2016.

PASOLD, César. Metodologia da pesquisa jurídica: teoria e prática. 12. ed. São Paulo: Conceito, 2011. POPPER, Karl R. A lógica da pesquisa científica. 9. ed. São Paulo: Cultrix, 2008.

POSNER, Richard Allen. A problemática da teoria moral e jurídica. São Paulo: Martins Fontes, 2012. POSNER, Richard Allen. Fronteiras da teoria do direito. São Paulo: Martins Fontes, 2011.

REGLA, Josep Aguiló. Teoria geral das fontes do direito. Lisboa: Escolar, 2013.

RUSSELL, Bertrand Arthur William. História do pensamento ocidental. 21. ed. Rio de Janeiro: Nova Fronteira, 2017.

SALAMA, Bruno Meyerhof. O que é direito e economia. [S.I.], 2016. Disponível em: https://works. bepress.com/bruno_meyerhof_salama/16/. Acesso em: 25 maio 2018.

SCHIOPPA, Antonio Padoa. História do direito na Europa: da idade média à idade contemporânea. São Paulo: Martins Fontes, 2014.

SHOOK, John Robert. Os pioneiros do pragmatismo americano. Rio de Janeiro: DP\&A, 2002.

STANLEY, M. L.; DOUGHERTY, A. M.; YANG, B. W.; HENNE, P.; DE BRIGARD, F. Reasons probably won't change your mind: the role of reasons in revising moral decisions. Journal of Experimental Psychology: general, [S.I.], v. 147, n. 7, p. 962-987, 2018. Disponível em: http://dx.doi.org/10.1037/ xge0000368. Acesso em: 06 ago. 2018.

STRECK, Lenio Luiz. Verdade e consenso: constituição, hermenêutica e teorias discursivas. 4. ed. São Paulo: Saraiva, 2011.

STRUCHINER, Noel. Como os juízes decidem os casos difíceis do direito? In: STRUCHINER, Noel; TAVARES, Rodrigo de Souza (org.). Novas fronteiras da teoria do direito: da filosofia moral à psicologia experimental. Rio de Janeiro: PUC Rio, 2014. p. 171-219.

WISBECK, A.; MEDEIROS, A.; COSTA, D. P.; ARAÚJO, S. Presidente do TJ e secretário de Saúde firmam convênio para ampliar alcance do NAT-SC. Florianópolis: Poder Judiciário de Santa Catarina, 2017. Disponivel em: https://portal.tjsc.jus.br/web/sala-de-imprensa/-/presidente-do-tj-e-secretario-desaude-firmam-convenio-para-ampliar-alcance-do-nat-sc. Acesso em: 07 ago. 2018.

ZANON JUNIOR, Orlando Luiz. Teoria complexa do direito. 2. ed. Curitiba: Prismas, 2015.

Recebido em: 14/01/2019

Aprovado em: 07/02/2019 